\title{
Weakness and Fluid Overload Hinder Weaning. Or Do They?
}

Weaning from mechanical ventilation is still a major challenge in critical care units. Prolonged ventilation is clearly associated with poor prognosis and increased mortality. For this reason, in recent years, many studies have aimed to identify which patients are ready to breathe on their own. Despite some controversial conclusions, most of us have included daily interruption of sedation, light sedation, and early mobilization to accelerate weaning in our practice. Despite these strategies, the rate of weaning and extubation failure in the last 15 years has remained as high as $13-18 \% .{ }^{1}$ While we strive to discover the reasons for failure, we continue to do everything in our power to reduce the risk of keeping patients ventilated longer than absolutely necessary. The challenge is not only to identify which patients are ready to breathe without assistance, but also which ones will pass a spontaneous breathing trial (SBT) and be successfully extubated. This issue of RESPIRATORY CARE includes 2 articles ${ }^{2,3}$ exploring 2 reasons for failure: weakness and fluid balance.

De Jonghe et $\mathrm{al}^{4}$ first described the relationship between limb and respiratory muscle weakness. They measured maximum inspiratory and expiratory pressures and vital capacity to evaluate respiratory strength and used the Medical Research Council scale to evaluate limb weakness, 2 factors that were closely correlated. Another study ${ }^{5}$ demonstrated that handgrip strength, an easy-to-measure variable, showed a good correlation with the accepted standard for weakness, the Medical Research Council scale.

In this issue of Respiratory CARE, Cottereau et $\mathrm{al}^{2}$ took this idea one step further and aimed to evaluate whether handgrip strength, as a surrogate for respiratory muscle function, predicts weaning and extubation success. The authors found that subjects with simple weaning had greater handgrip strength based on a single measurement on the first day of weaning before the first SBT, suggesting that they were strong enough to breathe spontaneously.

\footnotetext{
The authors have disclosed no conflicts of interest.
}

Correspondence: Rafael Fernandez MD PhD, Intensive Care Department, Fundació Althaia, Dr Joan Soler 1, 08243 Manresa, Barcelona, Spain. E-mail: rfernandezf@althaia.cat.

DOI: $10.4187 /$ respcare.04264
However, handgrip strength was not associated with extubation failure defined as re-intubation or unscheduled noninvasive ventilation within $48 \mathrm{~h}$ after extubation. One can argue that a single measurement of strength is unlikely to predict weaning when the patient will not be extubated until a few days later. It would be interesting to know if the strength measured on the actual day of extubation might be a better predictor of extubation failure.

See the Original Study on Pages 1091, 1097

However, successful weaning is not only related to strength but is also influenced by fluid imbalance. In the last 10 years, a few interesting studies have been published on weaning and fluid balance. In one observational study, Upadya et $\mathrm{al}^{6}$ found a correlation between negative fluid balance in the $24 \mathrm{~h}$ before an SBT and extubation success, suggesting that approaching weaning with a positive balance might be detrimental. Similarly, in a large multicenter observational study, Frutos-Vivar et al $^{7}$ reported that one of the risk factors for re-intubation was a positive fluid balance in the $24 \mathrm{~h}$ before extubation. Finally, Mekontso Dessap et $\mathrm{al}^{8}$ reported a multi-center randomized controlled trial comparing the effects of B-type natriuretic peptide-guided versus physician-guided fluid management on weaning outcome. The B-type natriuretic peptide-guided group received more fluid restriction and diuretics, resulting in a more negative median fluid balance during weaning and a shorter time to successful weaning and extubation. Electrolyte imbalance, renal failure, and shock did not differ between groups.

In this issue of Respiratory CARe, Antonio et $\mathrm{al}^{3}$ reported the results of an observational study on 250 subjects receiving mechanical ventilation for $>24 \mathrm{~h}$. When they examined the fluid balance in the $48 \mathrm{~h}$ before the SBT, they found no differences between subjects who successfully passed the SBT and those who failed it. These unexpected results might be related to some differences with previous studies. In Antonio et al's study, ${ }^{3}$ the mean fluid balance was positive in both groups and higher than in prior studies, ${ }^{7,8}$ where all the groups that successfully passed the SBT had a negative balance. The rate of SBT failure was also considerably higher in Antonio et al's study $^{3}$ than in the others (20\% vs $\left.\left.13 \%\right)\right)^{7,8}$ In this sce- 
nario, the possible role of negative fluid balance could be obscured by the low number of subjects who actually achieved a negative balance, making it more difficult to know whether other factors that influence extubation failure (eg, weakness, oversedation, heart failure) were more prominent in this group, thus reducing the likelihood of any positive effects of fluid balance emerging. However, their results provide additional evidence that patients with COPD may benefit from negative fluid balance.

After reading this editorial and the papers it discusses, readers might get the impression that there is nothing we can do to improve extubation success rates. However, the fact that no statistically significant differences were found does not mean that these factors are not important. In a multifaceted issue such as weaning failure, where the effects of any single factor can only be revealed after those of all possible confounding factors (cardiac dysfunction, undernutrition, agitation, upper airway obstruction, or pneumonia) are excluded, it seems unrealistic to seek a single factor that can explain a wide proportion of cases.

Despite all the controversies and the lack of strong evidence for many common practices in the ICU, no one would ever suggest that fluid overload or weakness is beneficial, so we would do well to avoid them. Nevertheless, delaying extubation is also detrimental. Thus, only a real test of patients' ability to breathe spontaneously should guide physicians in determining when they can be extubated. To ensure successful extubation, we need to start before weaning, avoiding fluid overload and factors related to weakness such as oversedation and lack of early mobilization.
Carles Subirá MD

Rafael Fernandez MD PhD

Intensive Care Department Fundació Althaia

Universitat Internacional de Catalunya Centro de Investigación Biomédica en Red de Enfermedades Respiratorias (CIBERES)

Manresa, Barcelona, Spain

\section{REFERENCES}

1. Boles JM, Bion J, Connors A, Herridge M, Marsh B, Melot C, et al. Weaning from mechanical ventilation. Eur Respir J 2007;29(5):1033-1056.

2. Cottereau G, Dres M, Avenel A, Fichet J, Jacobs FM, Prat D, et al. Handgrip strength predicts difficult weaning but not extubation failure in mechanically ventilated subjects. Respir Care 2015;60(8): 1097-1104.

3. Antonio AC, Teixeira C, Castro PS, Savi A, Oliveira AP, Gazzana MB, and Knorst M. 48-Hour fluid balance does not predict a successful spontaneous breathing trial. Respir Care 2015;60(8):1091-1096.

4. De Jonghe B, Bastuji-Garin S, Sharshar T, Outin H, Brochard L. Does ICU acquired paresis lengthen weaning from mechanical ventilation? Intensive Care Med 2004;30(6):1117-1121.

5. Bittner EA, Martyn JA, George E, Frontera WR, Eikermann M. Measurement of muscle strength in the intensive care unit. Crit Care Med 2009;37(10 Suppl):S321-S330.

6. Upadya A, Tilluckdharry L, Muralidharan V, Amoateng-Adjepong Y, Manthous CA. Fluid balance and weaning outcomes. Intensive Care Med 2005;31(12):1643-1647.

7. Frutos-Vivar F, Ferguson ND, Esteban A, Epstein SK, Arabi Y, Apezteguía $\mathrm{C}$, et al. Risk factors for extubation failure in patients following a successful spontaneous breathing trial. Chest 2006;130(6):1664-1671.

8. Mekontso Dessap A, Roche-Campo F, Kouatchet A, Tomicic V, Beduneau G, Sonneville R, et al. Natriuretic peptide-driven fluid management during ventilator weaning: a randomized controlled trial. Am J Respir Crit Care Med 2012;186(12):1256-1263. 